\title{
Safety and Effectiveness Outcomes of a Novel Sterile Titanium Clip Device-based Heart Valve Surgery in a Preclinical Disease Model
}

Bin Li

Fuwai Hospital, Chinese Academy of Medical Sciences https://orcid.org/0000-0002-7614-8488

\section{Guangxin Yue}

Fuwai Hospital State Key Laboratory of Cardiovascular Disease

Jinyan Zhu

Fuwai Hospital State Key Laboratory of Cardiovascular Disease

\section{Min Zhang}

Fuwai Hospital State Key Laboratory of Cardiovascular Disease

\section{Baiqing Yang}

Fuwai Hospital State Key Laboratory of Cardiovascular Disease

Jiafei Luo

Fuwai Hospital State Key Laboratory of Cardiovascular Disease

\section{Yang Sun}

Fuwai Hospital State Key Laboratory of Cardiovascular Disease

\section{Leisheng Zhang}

Shandong Qianfoshan Hospital

Xin Wang ( $\sim$ fuwaiwangxin@188.com )

Fuwai Hospital, Chinese Academy of Medical Sciences

\section{Research}

Keywords: Sterile titanium clip devices, Preclinical evaluation, Valvular heart disease, Heart Valve Surgery,

Safety and effectiveness

Posted Date: June 23rd, 2021

DOI: https://doi.org/10.21203/rs.3.rs-631325/v1

License: (c) (1) This work is licensed under a Creative Commons Attribution 4.0 International License.

Read Full License 


\title{
Safety and Effectiveness Outcomes of a Novel Sterile Titanium Clip Device-based Heart Valve Surgery in a Preclinical Disease Model
}

\author{
Bin Li', Guangxin Yue ${ }^{1}$, Jinyan Zhu' ${ }^{1}$, Min Zhang ${ }^{1}$, Baiqing Yang ${ }^{1}$, Jiafei Luo ${ }^{1}$, Yang Sun ${ }^{2}$, \\ Leisheng Zhang ${ }^{3,4}$, Xin Wang ${ }^{1}$ \\ * Correspondence: fuwaiwangxin@188.com (Xin Wang); \\ leisheng_zhang@163.com (Leisheng Zhang).
}

\begin{abstract}
Background: Valvular heart disease (VHD) is a major subtype of life-threatening myocardial disease with high mortality, and in particular, among inpatients with degenerative valve diseases. There is an urgent need for the evaluation of the operability, effectiveness and safety of the novel sterile titanium clip device-based valve surgery with minimal level of invasion for VHD administration via preclinical studies.

Methods: 18 small fat-tail sheep were prepared with extracorporeal circulation and performed upon thoracotomy and mitral valve shaping ring implantation. A total of 12 needles were conducted for mitral annulus suture, including 6 needles by utilizing the novel sterile titanium clip device (denoted as the experimental group) and another 6 needles by manual knotting (denoted as the control group), and the self-comparison was made at the indicated timepoints after surgery (30-day, 60-day, 90-day, 180-day). Along with recording the knotting time, echocardiography and blood tests were performed, with samples collected at the aforementioned timepoints. Pathological examination of the heart and vital organs was conducted to evaluate the safety and effectiveness of the implanted device.
\end{abstract}

Results: Of the 18 sheep, 16 survived the operation for past-operation experimental data collection, including 3 at day 30, 3 at day 60, 4 at day 90, and 6 at day 180, respectively. Compared to the control group, the operation time was significantly reduced with clip implantation $(\mathrm{P}<0.01)$. The mitral valve forming ring was fixed firmly without disengagement or displacement, endothelializations were successful, with no peri-valvular leakage or marked thrombosis observed. The rate of thrombosis caused by thread ends in the experimental group was significantly higher than that in the control group at day 90, whereas no significant difference at day 180 . Notably, with exception of two cases with visceral complications such as diffuse renal infarction caused by thromboembolism and small focal renal infarction, no significant differences in inflammatory response and other tissue responses or embolisms were observed in other organs.

Conclusions: The novel aseptic clip device is much simpler and more convenient for significantly shortening the knot tying time during the flap annular implantation process, which demonstrated overall effectiveness and safety compare to manual knot tying.

Keywords: Sterile titanium clip devices, Preclinical evaluation, Valvular heart disease, Heart Valve Surgery, Safety and effectiveness. 


\section{Introduction}

Valvular heart disease (VHD), including mitral regurgitation and aortic stenosis, remains the major subtypes of heart disease, and in particular, with increased prevalence of degenerative valve diseases in industrialized countries (Iung and Vahanian, 2011;Wojakowski and Baumgartner, 2019). According to the large-scale community echocardiographic surveys, the overall mortality rate of patients with VHD is $35-75 \%$ higher than that in the common population(Iung and Vahanian, 2011; Shah and Solomon, 2016). Of the over 2 million cases with VHD, over 80,000 of cases in the department of cardiothoracic surgery receive cardiac valve treatments each year in China(Mrsic et al., 2018; d'Arcy et al., 2016). The degenerative VHD relates to a variety of heterogeneous conditions (e.g., age, habitus, heredity), which collectively injure the intensive physical activity and render decision-marking for intervention complex. Generally, the work-up for inpatients with VHD includes the thorough history, clinical symptoms, evaluation of the valvular abnormality, and quantification of valve dysfunction as well. During the last decades, considerable headway has been made by therapeutic interventions such as diagnostic imaging, interventional cardiology, percutaneous mitral valve repair and transcatheter aortic valve implantation, which efficaciously helps alleviate pain of patients with high risk and even contraindications for surgery(Iung and Vahanian, 2011).

A cohort of iateria have been developed for VHD management such as transcatheter valve replacement and non-surgical conservative therapy. Surgical procedure under cardiopulmonary bypass is the preformed option for the heart valve diseases including severe thickening, deformity and limited movement(Mrsic et al., 2018;Hutt and Desai, 2020). While cardiac valve surgery under cardiopulmonary bypass (CPB) has prominent advantages in clinical application, the procedures are extremely complicated and with potential ensued complications of CPB(Wojakowski and Baumgartner, 2019). Gather data in published literatures have shown that the prolonged cardiopulmonary bypass and aortic occlusion are associated with a significantly increased rate of cerebrovascular events, multiple organ dysfunction after cardiac surgery, and death(Hollenberg, 2017). As to heart valve repair or replacement, the operation time is usually long due to the reduplication, inconvenience and consistency of knotting operation in deep surgery and the accompanied peri-valval leakage as well(Hutt and Desai, 2020).

Herein, on the basis of a small fat-tail sheep-based VHD disease model, we took advantage of a novel sterile titanium clip device for the in vivo safety and effectiveness evaluation upon VHD treatment. Strikingly, with the aid of the aforementioned device, we confirmed the efficacious knotting of sutures during VHD, together with the application prospects in shortening operation time, improved the quality of valve fixation, and alleviated postoperative complications.

\section{Methods}

\section{Animals and ethical approval}

A total of 18 experimental small fat-tail sheep (16 females and 2 males, 40-60 kg per body weigh) were procured from Laboratory Animal Center, Fuwai Hospital, Chinese Academy of Medical Sciences \& Peking Union Medical College. This study adopted the self-contrasted method, the mitral annulus implantation by either titanium clip-based surgery or manual knotting-based surgery were conducted in the same individual. All procedures of the experiment were approved by the Ethical Committee of Fuwai Hospital, Chinese Academy of Medical Sciences \& Peking Union Medical 
College (Approval No. 0097-2-18-HX(X)) and in accordance with the Standard Operation Procedures (SOP) as we previously described(Hou et al., 2020;Zhang et al., 2021).

\section{The application of novel sterile titanium clip device}

The Easy-Knot devices consist of sterile titanium clip (with titanium pins) and disposable sterile clip device, were purchased from Beijing Maidifeng Medical Technology Co. Ltd, Beijing, China) (Figure 1). The titanium pins in the titanium clip are the implanted parts for each suture fixation. The working principle is the coordination of titanium clip and clamp device in operation based on the compression and deformation of the metal tube to clamp the suture line instead of hand stitching. Simultaneously, the operators then employ the blade placed in the front to cut off the excess suture and finish knotting and cutting the suture.

\section{Animal anesthesia}

Before surgical operation, the aforementioned small fat-tail sheep were preoperative fasted and water deprived for $24 \mathrm{~h}$ and $8 \mathrm{~h}$, respectively. Afterwards, the sheep were incipiently narcotized by utilizing $4 \mathrm{mg} / \mathrm{kg}$ disoprofol (WZS-50F6), followed by weighing, skin preparation, body surface ultrasound (GE E9). The sheep were sent to the operation room for surgery after endotracheal intubation. During the operation, Isoflurane was used for further maintaining anesthesia with the anesthetic equipment (Drager Primus) during the operation.

\section{Surgical suture}

The experimental sheep were put in the right decubitus position on the operating table and disinfected with iodophor disinfectant. An incision was carried out on the left chest wall, and the scalpel entered chest cavity between the 3rd and 4th rib. The pericardium was cut-through (COVIDIEN Force FX-8C), and followed by traction and suspension to establish extracorporeal circulation (GE Innova2100). The left atrium was opened and the mitral valve was exposed after cardiac arrest. Then, the mitral ring was placed with intermittent suture, and 6 needles $(2$ needles for the anterior disc ring, 4 needles for the posterior disc ring) by utilizing the novel sterile titanium clip device (the experimental group) and another 6 needles by manual knot (the control group) were sutured along the mitral ring, which were fixed by the novel sterile titanium clip device and a conventional manual knot. Meanwhile, the knotting time in each group was recorded. After that, the left atrium was closed, cardiopulmonary bypass was stopped, the heart beating was resumed, and hemostasis was conducted as well. Finally, the drainage tubes were placed between the 6th and 7th intercostals, and the chest was closed layer by layer. During the operation, the electrocardiograph (ECG), arterial blood pressure (Philips, MP60), heart rate (Philips IntelliVue MP70), body temperature, blood gas (Abbott i-STAT1) and ACT (HEMOCHRON Jr Signature) of the experimental animals were closely monitored. Additionally, corresponding drugs were given according to intraoperative animal signs and anesthetic conditions as well.

\section{Postoperative care}

Based on postoperative standard operating procedures, postoperative care including postoperative ICU nursing, ventilator assisted breathing, continuous monitoring of blood pressure and electrocardiogram (Philips, MP60), was performed to maintain the circulation stability, and vasoactive drugs were given when necessary. Once the sheep gradually recovered and resumed autonomous respiration, the ventilator and endotracheal intubation was concurrently removed, and replaced by nasal oxygen assistance. The pleural drainage tube was removed depended on the liquid 
drainage volume and characteristics of the pleural drainage bottle were carefully recorded (the drainage volume $<20 \mathrm{~mL} / \mathrm{h}$ ).

After regaining consciousness and eating and defecating normally, the sheep were transferred to the feeding area, and diet and water consumption were strictly controlled for one week after the operation. The mental state, appetite, respiration, wound complications and other potentially adverse symptoms of the animals were observed daily, and the surgical incisions were disinfected at the meantime.

\section{Postoperative anti-infection}

Postoperative anti-infection was conducted to prevent sheep from secondary infection and the resultant death. In details, 4.8 million unit's penicillin and $0.2 \mathrm{~g}$ amikacin per time was intramuscularly injected for 7 days (two times each day). Anticoagulant treatment with Aspirin (100 $\mathrm{mg}$ per time, orally, once a day) and warfarin $(6 \mathrm{mg}$ per time, orally, once a day) were continued from the day after surgery to the end of the experiment. Heparin with low molecular weight (6000 IU per time, subcutaneously, twice a day) was injected immediately after surgery and lasted for 3 days.

\section{Data acquisition}

According to the experimental schedule, the consecutive follow-up examinations were performed before, during, after the operation at $0 \mathrm{~h}, 72 \mathrm{~h}, 30 \mathrm{~d}, 60 \mathrm{~d}, 90 \mathrm{~d}$ and $180 \mathrm{~d}$. The detailed information was showed in Table 1. For instance, the blood routine test consists red blood cell (RBC) count, white blood cell (WBC) count, platelet count, hemoglobin concentration. The blood biochemical test includes lactate dehydrogenase, creatine kinase, creatinine, urea nitrogen, alanine aminotransferase, aspartate aminotransferase as we described recently(Wei et al., 2020). Coagulation test includes PT International Standard Ratio (INR) and activated partial thromboplastin time, as well as free hemoglobin.

Histopathological examination was conducted as we recently described with several modification(Zhao et al., 2019; Hou et al., 2020). In details, samples were collected from each organ, including the left and right ventricles of the heart and ventricular septum, bilateral lungs, liver, spleen, kidneys, and cerebellum. After paraffin embedding and sectioning, hematoxylin-eosin staining (H\&E staining) was performed, followed by image analysis using the Olympus BX51 microscope and Image-Pro Plus6.0 Image analysis software as we reported(Zhang et al., 2020).

Scanning electron microscope (SEM) analysis was performed to evaluate the endothelialization as we recently reported(Zhang et al., 2021). In details, the cardiac tissues were fixed with $2.5 \%$ Glutaraldehyde (v/v) and 1\% osmic acid (v/v) (Sigma-Aldrich, St Louis, USA), and followed by dehydration with gradient alcohol and Isoamyl acetate. After that, the samples were dried in critical point dryer and sprayed by vacuum ion. The ultrastructure of the samples was observed by using the SEM (JSM-5050, Japan), including the fibrin and platelet deposition, the extent of new intima growth, and thrombosis. The percentage of new intima covered area (NICA) was calculated based on 5 random field of view: NICA $\%=($ neointimal area $/$ material area $) \times 100 \%$.

\section{Safety and effectiveness evaluation}

The safety and effectiveness evaluation of the novel sterile titanium clip device-based treatment upon the small fat-tail sheep-based VHD disease model was conducted from the following four aspects. Firstly, evaluation of stability of fixed molding ring was carried out based on the occurrence of loose 
and missing titanium screws, fixation reliability of forming ring and peri-valve leakage or not. Secondly, evaluation of mitral valve integrity was conducted based on the occurrence of defects, stenosis, prolapse, incomplete closure, perforation and excrescence. Thirdly, biocompatibility evaluation was done based on the occurrence of thrombogenesis (Table 2), endothelial change rate or not as recently reported by Zheng and the colleagues(Zheng et al., 2019). Fourthly, evaluation criteria for local response of implant materials were finished according to the professional standards (GB/T16886.6- 2015/ISO10993-6:2007) based on the occurrence of inflammatory response, other tissue reactions.

\section{Statistical analyses}

All data in the study were statistically analyzed by utilizing the SPSS 16.0 software as we previously described(Zhang et al., 2018; Wei et al., 2019; Huo et al., 2020; Liu et al., 2021). In details, $t$ test was used between the data groups conforming to normality, whereas the non-parametric test was used between the data groups not conforming to normality instead. All the data were shown as mean $\pm \mathrm{SD}$, and $\mathrm{P}<0.05$ was considered statistically significant. ${ }^{*}, \mathrm{P}<0.05 ; * *, \mathrm{P}<0.01 ; * * *, \mathrm{P}<0.001$; NS, not significant.

\section{Results}

\section{Heart valve surgery and application of the novel titanium sterile titanium clip device}

In this study, we used the small fat-tail sheep model to mimic the HVD associated cardiac trauma and evaluate the applicability of the novel titanium sterile titanium clip device-based heart valve surgery, we incipiently took advantage of the small fat-tail sheep-based disease model. Of the enrolled 18 sheep, two died during the operation or 171 days after, respectively. The death during operation was caused by the presence of atrial septal deficiency. During the surgery, air intake occurred at the atrial septal defect, and extracorporeal circulation was stopped during atrial septal repair, which collectively resulted in cardiac arrhythmia and heart failure after cardiac relapse. Pathological manifestations such as blood spots on the surface of the heart, multiple bleeding in the myocardium, and congestion and bleeding in both lungs manifested. The death at day 171 after surgery was ascribed to the mismatch of the mitral valve forming ring from the animal valve ring, which further resulted in prolonged operation time, postoperative mitral valve regurgitation, slow heart rate, together with less food intake, diarrhea, and thus the excessive deterioration of body function and pathological manifestations of bilateral lung stasis. Furthermore, pathological examination revealed that the cause of death was unrelated to the novel experimental materials.

Exclude the above stated 2 cases, a total of 16 sheep were included for the further analyses, including 3, 3, 4, and 6 sheep in the 30-day's group, 60-day's group, 90-day's group, and 180-day's group, respectively. After the mitral rings were implanted in 16 enrolled sheep, sterile titanium clamps and disposable sterile clamps were used to knot and cut sutures along the anterior and posterior lobe of the mitral valve ring, hand knot and cut sutures along the other half of the mitral valve ring. A total number of 96 knots in 16 sheep were done by utilizing the titanium clip device. During the process of knotting, it was convenient for the titanium clip to penetrate the clip device, and the suture to be knotted and cut off was more convenient, and the suture was well fixed without loosening or falling off.

\section{The effectiveness outcomes of the novel titanium sterile titanium clip device-based treatment}


To assess the potential superiority of the novel titanium sterile titanium clip device-based treatment over manual knotting, we initially recorded the knotting and cutting time between the manually control group and the experimental group with titanium clip and clip (Table 3). According to the statistical analyses, we verified that both the total and average knotting and cutting time in the experimental group were significantly shorter compared to those in the control group, respectively $(\mathrm{P}<0.001)$. Meanwhile, as confirmed by the image analyses of the pathological implantation site, the implant site of the forming ring was the mitral valve, which was fixed by 6 titanium screws and 6 hand-knotted sutures in each case. Notably, all of the aforementioned forming rings in the surgical sites were congruously firm without disengagement and displacement.

\section{Safety outcomes of the novel titanium sterile titanium clip device-based treatment}

Having clarified the inspiring effectiveness of the novel treatment, we are curious whether there's any potential safety hazards of the implanted titanium sterile titanium clip device. Therefore, we primarily conducted peripheral blood test and found that both the blood routine (e.g., RBC, HGB, PLT) and liver and kidney function indexes (e.g., LDH, CRE, BUN, ALT, AST) returned to the normal range by reexamination at 30 days after operation, and minimal abnormality was observed (Table 4). Similarly, there were no significant differences in hemoglobin and platelet counts after surgery compared with those before surgery $(\mathrm{P}>0.05)$. The free hemoglobin was $20-40 \mathrm{mg} / \mathrm{dL}$ before surgery and 50-80 mg/dL 180 days after surgery, which collectively indicated no significant hemolysis occurred during the treatment.

Therewith, we turned to ultrasonic examination to evaluate the status of the surgical site of the heart. Notably, there was no abnormality in the function of the mitral valve after operation whereas significant differences were observed in the peak flow rate and the peak pressure difference $(\mathrm{P}<0.05)$. On the contrary, there were no significant differences in the mean flow rate and the mean pressure difference $(\mathrm{P}>0.05)$. Meanwhile, we noticed that two sheep showed a spot of peri-valvular leakage, while with slight and moderate mitral regurgitation after operation, respectively (Table 5). Also, two and one sheep manifested slight and moderate mitral regurgitation 30 days after surgery, respectively. On the basis of ultrasonic examination (e.g., MVF, PSV, PPG, MR), we presumed that the distinctions in mitral regurgitation before and after surgery among the aforementioned sheep largely attribute to the potential effects of artificial operation factors (Table 5).

To evaluate the potential impact of the novel titanium sterile titanium clip device upon the morphology of the implant site, we dissected the implanted forming ring in the mitral valve fixed by 6 titanium screws and 6 hand-knotted sutures and found that all of them were firm without visible disengagement and displacement (Figure 2a-2d). There was no peri-leakage on the fixed suture side of titanium nail, whereas one peri-leakage was observed on the fixed side of the control hand-knotted suture. Indiscriminatingly, the mitral valve was intact in all sheep without defect, stenosis, prolapse, insufficiency or perforation.

Ulteriorly, we further analyzed the endothelialization process of the implanted titanium nail surface by utilizing the scanning electron microscope (SEM) test. Generally, the endothelialization of titanium nails was satisfactory (Figure 3a). In details, endothelial coating initiated in the first month and gradually increased with as time went on. The average endothelialization rate of the experimental group with implanted titanium nails in the 30-day's group $(22.67 \%)$ was significantly lower than that in the control manual group $(98.33 \%)$, then gradually approached that in the control group in the 60day' group (the experimental group vs the control group, 62.67\% vs 98.33\%), the 90-day' group (the 
experimental group vs the control group, $66 \%$ vs100\%) and the 180-day' group (the experimental group vs the control group, $90.5 \% \pm 15.28 \%$ vs $100 \% \pm 0.00 \%, \mathrm{P}=0.094$ ), respectively(Figure $3 b$ ).

Aiming to further explore the potential harm of the novel titanium sterile titanium clip device, we compared the statuses of thrombosis in the experimental and control groups. Intuitively, even though we didn't observed thrombosis in the metallic part of the titanium nail, yet thread end of titanium nail was easy to form instead (Figure 4a-4b). In details, the thrombosis rate of the titanium clip devicebased therapy was higher than that in the manual operation in the 30-day's group (77.78\% vs 5.56\%), the 60-day's group $(27.78 \%$ vs $5.56 \%)$, the 90 -day's group $(37.50 \%$ vs $0.00 \%)$, whereas no significant difference in the 180 -day' group $(13.89 \% \pm 22.15 \%$ vs $0.00 \%, \mathrm{P}=0.093)$. According to the tissue sections and H\&E staining, the diameter of thrombus in all groups were small with a mean diameter less than $5 \mathrm{~mm}$ (Figure 5a) and pathological examination revealed a slight thrombosis as well. Thus, thrombus formation at the tip of the line in both groups was in the acceptable range without limitation to potential clinical trials. Compared to the control group, the thrombus levels in the experimental group at day 30 (1.33 vs 0.33 ), day 60 (0.67 vs 0.33$)$, day 90 (1.0 vs 0.0$)$, whereas no significant difference at day 180 was observed $(0.33 \pm 0.52$ vs $0.00 \pm 0.00, \mathrm{P}=0.087)$. Meanwhile, local tissue inflammation and other tissue responses to titanium clip-based knotting were comparable to those by manual knotting such as cardiovascular formation, fat infiltration and calcification during treatment (Figure 5a). Notably, except those in the 30-day's group $(0.67$ vs $4.0, P<0.01)$ as well as the other histologic reaction, no significant differences in the inflammatory reaction and the number of fiber wraps between the two groups were observed at the rest timepoints (60-day's, 90-day's, 180day's) (Figure 5b-5c). In details, fiber wrapping could be seen at each time point of the hand-knotted suture, and the number of fibers wrapped on the surface of titanium screws increased gradually with the prolongation of experiment time (7/18 in the 30-day's group, $17 / 18$ in the 60-day's group, $24 / 24$ in the 90-day's group and 36/36 in the 180-day's group) (Figure 5d).

Additionally, by conducting gross anatomy and histopathological examination of the important organs, we didn't notice significant differences in inflammatory responses or other tissue responses in all of the aforementioned groups during the throughout period of treatment as well (Figure 6a-6d). As to visceral complications, we found 1 case of diffuse renal infarction (area ratio $=20 \%$ ) and 1 case of small focal renal infarction (area ratio $<5 \%$ ) were caused by thromboembolism, 1 case of small cardiac infarction caused by intraoperative air embolism (area ratio $<5 \%$ ), together with 1 case of myocardial ischemia reperfusion injury. No other embolism in relative organs was observed. Taken together, our data confirmed the safety of the novel titanium sterile titanium clip device-based treatment in preclinical studies.

\section{Discussion}

In recent years, minimally invasive valve surgery with small incision has been rapidly popularized and promoted. Clinical attempts have shown that minimally invasive valve surgery with a small incision can achieve the same therapeutic effect as traditional large-scale incision valve surgery, and minimally invasive valve surgery with a small incision also has many advantages such as postoperative pain relief, good recovery of respiratory function, short hospital stay and cosmetic effect(Galloway et al., 2009; Cheng et al., 2011; Iribarne et al., 2011). However, minimally invasive surgery also has conspicuous disadvantages including lengthy extracorporeal circulation time and aorta block time, poor heart exposure, high technical difficulty and the longer learning curve(Cheng et al., 2011; Iribarne et al., 2011), and in particular, the complexity of suture and knot operation and the resultant prolonged operation time are the major reasons(Lee et al., 2014). Worse still, the extended extracorporeal circulation time further led to the significantly increased risk of 
cerebrovascular and lethal events and multiple organ dysfunction after surgery(Roach et al., 1996). Thus, in this study, we took advantage of the novel sterile titanium clip device fixed suture in the mitral valve molding ring implantation operation to evaluate the in vivo effectiveness and safety, which collectively indicated the superiority over the control group with routine manual surgery to secure the suture and the rosy prospect as well.

In minimally invasive surgery, deep tissue suture and knotting under the condition of limited visual field and operating space have become the principal difficulty and the major obstacle for the promotion. To solve the issue, a variety of deep-knotting device have been developed by numerous medical corporations such as Autosuture Endo Stitch (Covidien, Mansfield, MA, USA)(Adams et al., 1995), Suture Assist (Ethicon Endo-Surgery, Cincinnati, OH, USA)(Pattaras et al., 2001) and Suture Cartridge(Kuniholm et al., 2005). Meanwhile, a series of strategies for suturing and fixing the device have been developed, including the needle holder knotting method(Asao et al., 2007), round needle replacement by flat needle to reduce the difficulty of holding suture needle(Ozawa et al., 2008), and the improved suture line method(Tan and Razvi, 2005). However, a certain number of fastening devices and knotting methods have defects such as limited application context (e.g., not cost-effective, cumbersome, special storage, prone to split seam), difficult operation (e.g., tie several knots in a piece of stitching and then cut the extra stitches separately) and low practicability (poor consistency of surgical suture, the higher incidence of perivalvular mitral leakage), and thus can't be popularized and applied in minimally invasive valve surgery(Lee et al., 2014). Distinguish from the aforementioned disadvantages, the novel sterile titanium clip device is capable of clamping the sutures and knotting by controlling the putter movement and the resultant deformation of titanium nails. The outer tube at the front end of the device is $30 \mathrm{~cm}$ long, which can efficaciously satisfy the knot tying of traditional surgical operation and be used for minimally invasive heart valve surgery as well.

Thrombosis and embolism are the key issues in safety evaluation. In this study, we found no thrombus formation on the surface of titanium nail, whereas the titanium nail end suture threads rather than hand knotted line heads were more inclined to form thrombosis, which might due to the easier decompaction of the braided fibers with the application of the sterile clamp device than with scissor cutting. According to the national standard for thrombus grading (GB/T14233.2-2005), the experimental thrombosis with a diameter less than $5 \mathrm{~mm}$ was no more than level 2, which was qualified and satisfied the slight and even no thrombosis. Therefore, based on the outcomes of the preclinical study as well as the aforementioned guidelines, we preliminarily deduced that the novel titanium-based device was consistent with the margin of safety without visible limitations for potential clinical applications in heart valve surgery including valvular heart disease (VHD). Nevertheless, the current evaluation of the safety and effectiveness of the titanium clip for VHD management in this study is limited and still needs systematical and meticulous dissection before clinical practice in future.

Based on the pathological examination, we found 1 case with thromboembolism caused by kidney diffuse infarction (area accounted for 20\%) and another 1 case with renal infarction (area accounted for $<5 \%$ ), whereas no other viscera embolism. The reasons for this can be summarized as three aspects. Firstly, the experimental titanium nail knot suture head end loss caused by blood clots; secondly, the loss of the formed thrombosis caused by the manual knotted line; thirdly, extracorporeal circulation in the process of operation has the risk of blood clots, and the possibility of clots caused by blood transfusion reaction. 
The effectiveness of aseptic titanium clip device-based therapy is also the focus in the field. Herein, by conducting multifaceted in vivo evaluation, we found that one single operation was adequate for finishing knotting and tangential at the same time, which was convenient, fast, reliable and consistent, especially for deep knotting. In details, the average time of tying and cutting sutures was about 3.6 seconds per stitch, which was one-eighth of that by traditional manual tying. Therefore, the novel aseptic titanium clip device-based therapy held the potential to significantly shorten the time of extracorporeal circulation and aortic occlusion and vastly reduce the risk of complications after heart surgery as well. Meanwhile, postoperative pathological gross anatomy showed that all the forming ring parts fixed by the titanium clip were firm without detachment, displacement, and leakage around the forming ring valve, and there were no significant differences from manual knotting. Notably, the statistical differences in endothelialization, number of fiber wraps, and thrombus formation in the uncut thread ends at day 30 could be gradually eliminated after surgery. Additionally, on the basis of gross anatomical and pathological examination, we observed the occurrence of slight hyperplasia of fibrous tissue with mild granulomatous reaction and slight calcification in the site of suture. However, the further evaluation of fibrotic lesions by fibrous tissue with $\mathrm{H} \& \mathrm{E}$ staining using Masson Trichrome staining and the potential immunodysfunction by CD45-based immunostaining was unavailable in this study.

Currently, considering the increasing domestic cardiovascular medical devices, there is an urgent need for standardized and specialized pre-clinical in vivo evaluation methods of the implanted cardiovascular devices to provide data support for the products entering clinical trials and practices. The novel sterile titanium clamp device evaluation method introduced in this study was accordance with the Chinese national drug supervision and administration of medical devices technical evaluation center (NMPA) and the United States food and drug administration (FDA). Also, the establishment of aforementioned assessment criteria was based on our in vivo preclinical evaluation experience of cardiovascular implant materials as well. Moreover, our findings provided overwhelming new reference for the establishment of a novel sterile titanium clamp device-based therapy in cardiac valvular surgery and relative in vivo preclinical evaluation of cardiovascular medical apparatus and instruments. Collectively, we herein showed that the application of the new aseptic clip device was qualified for significantly shortening the knot tying time during the flap annular implantation process, which was simple and convenient together with indiscriminate effectiveness and safety as manual knot tying.

\section{Abbreviations}

VHD, Valvular heart disease;CPB,Cardiopulmonary bypass;SEM,Scanning electron microscope;ACT, Activated clotting time;RBC, Red blood cell count; WBC, White blood cell count; HGB, Hemoglobin; PLT, Platelet; LDH, Lactic dehydrogenase; CK, Creatine kinase; CRE, Creatinine; BUN, Blood urea nitrogen; ALT, Alanine aminotransferase; AST, Aspartate transaminase; PT, Prothrombin time; INR, International normalized ratio; APTT, Activated partial thromboplastin time.

\section{Funding}

The work was supported by the project Youth Fund supported by Shandong Provincial Natural Science Foundation (ZR2020QC097), Project funded by China Postdoctoral Science Foundation (2019M661033), Science and technology projects of Guizhou Province (ZK-2021-107), Jiangxi key new product incubation program funded by Technical Innovation Guidance Program of Shangrao city (2020G002), Major Project of Fundamental Research Funds of the Central Public Welfare 
Scientific Research Institutes of the Chinese Academy of Medical Sciences (2018PT31048, 2019PT310013).

\section{Availability of data and material}

All data of the study are included in the published article. Meanwhile, the datasets of the current study are available from the corresponding author.

\section{Acknowledgments}

The authors thank the members in the Animal Experimental Centre, Beijing Key Laboratory of Preclinical Research and Evaluation for Cardiovascular Implant Materials, State Key Laboratory of Cardiovascular Disease, Fuwai Hospital, National Centre for Cardiovascular Disease, Chinese Academy of Medical Sciences and Peking Union Medical College for their technical supports. We thank Mr Jian Meng, Qingliang Zhou, and Zhiwei Ma in Beijing Med-zenith Medical Technology Co., Ltd. for their professional suggestions and technical supports as well.

\section{Author information}

\section{Affiliations}

${ }^{1}$ Animal Experimental Centre, Beijing Key Laboratory of Preclinical Research and Evaluation for Cardiovascular Implant Materials, State Key Laboratory of Cardiovascular Disease, Fuwai Hospital, National Centre for Cardiovascular Disease, Chinese Academy of Medical Sciences and Peking Union Medical College, Beijing, 100037, China

Bin Li, Guangxin Yue, Jinyan Zhu, Min Zhang, Baiqing Yang, Jiafei Luo, Xin Wang

2 Department of Pathology, Fuwai Hospital, National Centre for Cardiovascular Disease, Chinese Academy of Medical Sciences and Peking Union Medical College, Beijing, 100037, China

Yang Sun

${ }^{3}$ Shandong Provincial Key Laboratory of Translational Medicine for Rheumatic and Immune Diseases, Qianfoshan Hospital \& The First Affiliated Hospital of Shandong First Medical University, Ji-nan, 250014, China

Leisheng Zhang

${ }^{4}$ The Postdoctoral Research Station, School of Medicine, Nankai University, Tianjin, 300071, China

Leisheng Zhang

\section{Author Contributions}

Bin Li and Guangxin Yue: collection and assembly of data; Jinyan Zhu, Min Zhang, Baiqing Yang, Jiafei Luo, Yang Sun: collection and assembly of data and manuscript writing; Xin Wang, Bin Li and Leisheng Zhang: conception and design, data analysis and interpretation, manuscript writing and revision. All of the authors finally approved the manuscript. 


\section{Corresponding author}

Correspondence to Xin Wang and Leisheng Zhang.

\section{Ethics declarations}

\section{Ethics Approval and Informed Consent}

No human studies were carried out by the authors for this article. All the procedures of the animal experiment were approved by the Ethical Committee of Fuwai Hospital, Chinese Academy of Medical Sciences \& Peking Union Medical College (Approval No. 0097-2-18-HX(X)) and in accordance with the indicated Standard Operation Procedures (SOP).

\section{Competing Interests}

The authors declare no competing interests. 


\section{References}

1. Adams, J.B., Schulam, P.G., Moore, R.G., Partin, A.W., and Kavoussi, L.R. (1995). New laparoscopic suturing device: initial clinical experience. Urology 46, 242-245.

2. Asao, T., Yamaguchi, S., Tsutsumi, S., Mochiki, E., and Kuwano, H. (2007). Experimental results and early clinical experience with an easy method for intracorporeal knot tying using a novel laparoscopic needleholder. Surg Endosc 21, 1553-1556.

3. Cheng, D.C., Martin, J., Lal, A., Diegeler, A., Folliguet, T.A., Nifong, L.W., Perier, P., Raanani, E., Smith, J.M., Seeburger, J., and Falk, V. (2011). Minimally invasive versus conventional open mitral valve surgery: a meta-analysis and systematic review. Innovations (Phila) 6, 84-103.

4. D'arcy, J.L., Coffey, S., Loudon, M.A., Kennedy, A., Pearson-Stuttard, J., Birks, J., Frangou, E., Farmer, A.J., Mant, D., Wilson, J., Myerson, S.G., and Prendergast, B.D. (2016). Large-scale community echocardiographic screening reveals a major burden of undiagnosed valvular heart disease in older people: the OxVALVE Population Cohort Study. Eur Heart J 37, 3515-3522.

5. Galloway, A.C., Schwartz, C.F., Ribakove, G.H., Crooke, G.A., Gogoladze, G., Ursomanno, P., Mirabella, M., Culliford, A.T., and Grossi, E.A. (2009). A decade of minimally invasive mitral repair: long-term outcomes. Ann Thorac Surg 88, 1180-1184.

6. Hollenberg, S.M. (2017). Valvular Heart Disease in Adults: Etiologies, Classification, and Diagnosis. FP Essent 457, 11-16.

7. Hou, H., Zhang, L., Duan, L., Liu, Y., Han, Z., Li, Z., and Cao, X. (2020). Spatio-Temporal Metabolokinetics and Efficacy of Human Placenta-Derived Mesenchymal Stem/Stromal Cells on Mice with Refractory Crohn's-like Enterocutaneous Fistula. Stem Cell Rev Rep.

8. Huo, J., Zhang, L., Ren, X., Li, C., Li, X., Dong, P., Zheng, X., Huang, J., Shao, Y., Ge, M., Zhang, J., Wang, M., Nie, N., Jin, P., and Zheng, Y. (2020). Multifaceted characterization of the signatures and efficacy of mesenchymal stem/stromal cells in acquired aplastic anemia. Stem Cell Res Ther 11, 59.

9. Hutt, E., and Desai, M.Y. (2020). Management of valvular heart disease in the pregnant patient. Expert Rev Cardiovasc Ther 18, 495-501.

10. Iribarne, A., Easterwood, R., Chan, E.Y., Yang, J., Soni, L., Russo, M.J., Smith, C.R., and Argenziano, M. (2011). The golden age of minimally invasive cardiothoracic surgery: current and future perspectives. Future Cardiol 7, 333-346.

11. Iung, B., and Vahanian, A. (2011). Epidemiology of valvular heart disease in the adult. Nat Rev Cardiol 8, 162-172.

12. Kuniholm, J.F., Buckner, G.D., Nifong, W., and Orrico, M. (2005). Automated knot tying for fixation in minimally invasive, robot-assisted cardiac surgery. J Biomech Eng 127, 1001-1008. 
13. Lee, C.Y., Sauer, J.S., Gorea, H.R., Martellaro, A.J., and Knight, P.A. (2014). Comparison of strength, consistency, and speed of COR-KNOT versus manually hand-tied knots in an ex vivo minimally invasive model. Innovations (Phila) 9, 111-116; discussion 116.

14. Liu, M., Meng, Y., Zhang, L., Han, Z., and Feng, X. (2021). High-efficient generation of natural killer cells from peripheral blood with preferable cell vitality and enhanced cytotoxicity by combination of IL-2, IL-15 and IL-18. Biochem Biophys Res Commun 534, 149-156.

15. Mrsic, Z., Hopkins, S.P., Antevil, J.L., and Mullenix, P.S. (2018). Valvular Heart Disease. Prim Care 45, 81-94.

16. Ozawa, S., Morikawa, Y., Oguma, J., Kitagawa, Y., Asada, H., and Kitajima, M. (2008).

Development of a new flat needle and a reduced surface coating thread for endoscopic suturing. $J$ Surg Res 145, 266-271.

17. Pattaras, J.G., Smith, G.S., Landman, J., and Moore, R.G. (2001). Comparison and analysis of laparoscopic intracorporeal suturing devices: preliminary results. J Endourol 15, 187-192.

18. Roach, G.W., Kanchuger, M., Mangano, C.M., Newman, M., Nussmeier, N., Wolman, R., Aggarwal, A., Marschall, K., Graham, S.H., and Ley, C. (1996). Adverse cerebral outcomes after coronary bypass surgery. Multicenter Study of Perioperative Ischemia Research Group and the Ischemia Research and Education Foundation Investigators. $N$ Engl J Med 335, 1857-1863.

19. Shah, A.M., and Solomon, S.D. (2016). Valvular heart disease in older adults: seeking an ounce of prevention. Eur Heart J 37, 3523-3524.

20. Tan, A., and Razvi, H. (2005). Evaluation of a novel modified suture material designed to facilitate intracorporeal knot tying during laparoscopic surgery. J Endourol 19, 1104-1108.

21. Wei, Y., Hou, H., Zhang, L., Zhao, N., Li, C., Huo, J., Liu, Y., Zhang, W., Li, Z., Liu, D., Han, Z., Zhang, L., Song, B., Chi, Y., and Han, Z. (2019). JNKi- and DAC-programmed mesenchymal stem/stromal cells from hESCs facilitate hematopoiesis and alleviate hind limb ischemia. Stem Cell Res Ther 10, 186.

22. Wei, Y., Zhang, L., Chi, Y., Ren, X., Gao, Y., Song, B., Li, C., Han, Z., Zhang, L., and Han, Z. (2020). High-efficient generation of VCAM-1(+) mesenchymal stem cells with multidimensional superiorities in signatures and efficacy on aplastic anaemia mice. Cell Prolif, e12862.

23. Wojakowski, W., and Baumgartner, H. (2019). The Year in Cardiology 2018: Valvular Heart Disease. Eur Heart J 40, 414-421.

24. Zhang, L., Wang, H., Liu, C., Wu, Q., Su, P., Wu, D., Guo, J., Zhou, W., Xu, Y., Shi, L., and Zhou, J. (2018). MSX2 Initiates and Accelerates Mesenchymal Stem/Stromal Cell Specification of hPSCs by Regulating TWIST1 and PRAME. Stem Cell Reports 11, 497-513.

25. Zhang, L., Wei, Y., Chi, Y., Liu, D., Yang, S., Han, Z., and Li, Z. (2021). Two-step generation of 
mesenchymal stem/stromal cells from human pluripotent stem cells with reinforced efficacy upon osteoarthritis rabbits by HA hydrogel. Cell Biosci 11, 6 .

26. Zhang, L., Zou, L., Ma, Y., Feng, C., Zhan, R., Yang, H., Song, B., and Han, Z. (2020).

Multifaceted modifications for a cell size-based circulating tumor cell scope technique hold the prospect for large-scale application in general populations. Cell Biol Int.

27. Zhao, Q., Zhang, L., Wei, Y., Yu, H., Zou, L., Huo, J., Yang, H., Song, B., Wei, T., Wu, D., Zhang, W., Zhang, L., Liu, D., Li, Z., Chi, Y., Han, Z., and Han, Z. (2019). Systematic comparison of hUC-MSCs at various passages reveals the variations of signatures and therapeutic effect on acute graft-versus-host disease. Stem Cell Res Ther 10, 354.

28. Zheng, J.F., Qiu, H., Tian, Y., Hu, X.Y., Luo, T., Wu, C., Tian, Y., Tang, Y., Song, L.F., Li, L., Xu, L., Xu, B., and Gao, R.L. (2019). Preclinical Evaluation of a Novel Sirolimus-Eluting Iron Bioresorbable Coronary Scaffold in Porcine Coronary Artery at 6 Months. JACC Cardiovasc Interv 12, 245-255. 
Tables

Table 1. Data acquisition during the experimentation on sheep

\begin{tabular}{|c|c|c|c|c|c|c|c|c|}
\hline items & before & During & Oh & $72 \mathrm{~h}$ & 30-day & 60-day & 90-day & 180-day \\
\hline Basic information & $\mathrm{X}$ & $\mathrm{X}$ & $\mathrm{X}$ & $X$ & $X$ & $\mathrm{X}$ & $X$ & $X$ \\
\hline $\begin{array}{l}\text { Titanium clip and } \\
\text { manual Suture time }\end{array}$ & & $\mathrm{X}$ & & & & & & \\
\hline $\begin{array}{l}\text { Blood routine } \\
\text { examination }\end{array}$ & $\mathrm{X}$ & & & $\mathrm{X}$ & $\mathrm{X}$ & $\mathrm{X}$ & $\mathrm{X}$ & $\mathrm{X}$ \\
\hline Hepatorenal function & $X$ & & & $X$ & $X$ & $X$ & $\mathrm{X}$ & $\mathrm{X}$ \\
\hline $\begin{array}{l}\text { The binomial } \\
\text { coagulation }\end{array}$ & $\mathrm{X}$ & & & $X$ & $X$ & $\mathrm{X}$ & $X$ & $\mathrm{X}$ \\
\hline Free hemoglobin & $X$ & & & $X$ & $X$ & $\mathrm{X}$ & $X$ & $X$ \\
\hline $\begin{array}{l}\text { Transthoracic } \\
\text { echocardiography, } \\
\text { TTE }\end{array}$ & $\mathrm{X}$ & & $\mathrm{X}$ & $\mathrm{X}$ & $\mathrm{X}$ & $\mathrm{X}$ & $\mathrm{X}$ & $X$ \\
\hline Adverse events & $\mathrm{X}$ & $\mathrm{X}$ & $\mathrm{X}$ & $\mathrm{X}$ & $\mathrm{X}$ & $\mathrm{X}$ & $\mathrm{X}$ & $\mathrm{X}$ \\
\hline Pathology & & & & & $\mathrm{X}$ & $X$ & $\mathrm{X}$ & $\mathrm{X}$ \\
\hline
\end{tabular}

Note: $\mathrm{X}$ represents the required inspection item. 
Table 2. Classification criteria for thrombosis response (GB/T14233.2-2005)

\begin{tabular}{cl}
\hline Thrombus level & Thrombosis observation \\
\hline 0 & Free of Thrombosis \\
1 & Minor thrombosis, a blood clot or a very thin blood clot in one place \\
2 & $\begin{array}{l}\text { Minor thrombosis, tiny blood clots in several places } \\
\text { Moderate thrombosis, the blood clot covered less than half the length of } \\
\text { the implanted sample } \\
4\end{array}$ \\
& $\begin{array}{l}\text { Severe thrombosis, the blood clot covered more than half the length of the } \\
\text { implanted sample }\end{array}$ \\
& Vascular occlusion
\end{tabular}


Table 3. Calculation of the total and average knotting and cutting time during Heart valve surgery

\begin{tabular}{cccc}
\hline items & $\begin{array}{c}\text { The manually } \\
\text { control group }\end{array}$ & $\begin{array}{c}\text { the experimental group with } \\
\text { titanium clip and clip }\end{array}$ & P value \\
\hline $\begin{array}{c}\text { Total knotting and } \\
\text { cutting time (s) }\end{array}$ & $345.56 \pm 68.68$ & $157.31 \pm 58.84$ & $<0.001^{* * *}$ \\
$\begin{array}{c}\text { The average knotting } \\
\text { and cutting time (s) }\end{array}$ & $57.59 \pm 11.45$ & $26.22 \pm 9.81$ & $<0.001^{* * *}$ \\
\hline
\end{tabular}

Note: Mean $\pm \mathrm{SD}, * * *, \mathrm{P}<0.001$ 
Table 4. Blood test results during the experimentation on sheep

\begin{tabular}{|c|c|c|c|c|c|c|c|c|c|c|c|}
\hline \multirow{2}{*}{ Items } & \multirow{2}{*}{$\begin{array}{c}\text { oh }(\mathbf{n}=\mathbf{1 6}) \\
\text { Mean } \pm \\
\text { SD }\end{array}$} & \multicolumn{2}{|c|}{$72 \mathrm{~h}(\mathrm{n}=16)$} & \multicolumn{2}{|c|}{ 30-day $(n=16)$} & \multicolumn{2}{|c|}{ 60-day $(n=13)$} & \multicolumn{2}{|c|}{$90-$ day $(n=10)$} & \multicolumn{2}{|c|}{$180-$ day $(n=6)$} \\
\hline & & Mean \pm SD & $\begin{array}{c}\mathrm{P} \\
\text { value }\end{array}$ & Mean \pm SD & $\begin{array}{c}\mathrm{P} \\
\text { value }\end{array}$ & $\begin{array}{c}\text { Mean } \pm \\
\text { SD }\end{array}$ & P value & $\begin{array}{c}\text { Mean } \pm \\
\text { SD }\end{array}$ & $P$ value & $\begin{array}{c}\text { Mean } \pm \\
\text { SD }\end{array}$ & $P$ value \\
\hline $\begin{array}{c}\mathrm{RBC} \\
\left(10^{12} / \mathrm{L}\right)\end{array}$ & $11.79 \pm 1.04$ & $9.98 \pm 1.42$ & $\begin{array}{c}< \\
0.01^{* *}\end{array}$ & $11.17 \pm 1.10$ & 0.112 & $11.91 \pm 1.26$ & 0.769 & $12.63 \pm 1.15$ & 0.065 & $11.44 \pm 1.56$ & 0.552 \\
\hline $\begin{array}{c}\text { WBC } \\
\left(10^{9} / \mathrm{L}\right)\end{array}$ & $10.78 \pm 2.35$ & $12.87 \pm 3.61$ & 0.062 & $9.95 \pm 4.89$ & 0.548 & $7.90 \pm 1.96$ & $<0.01^{* *}$ & $7.05 \pm 1.49$ & $<0.01$ & $7.44 \pm 2.18$ & $<0.01^{* *}$ \\
\hline HGB (g/L) & $\begin{array}{c}121.31 \pm 11 \\
80\end{array}$ & $\begin{array}{c}102.69 \pm 14.5 \\
1\end{array}$ & $\begin{array}{c}< \\
0.01^{* *}\end{array}$ & $\begin{array}{c}118.88 \pm 11.9 \\
9\end{array}$ & 0.567 & $\begin{array}{c}126.00 \pm 11 \\
99\end{array}$ & 0.300 & $\begin{array}{c}132.70 \pm 14 \\
24\end{array}$ & $<0.01$ & $\begin{array}{c}128.17 \pm 18 \\
67\end{array}$ & 0.313 \\
\hline $\operatorname{PLT}\left(10^{9} / \mathrm{L}\right)$ & $\begin{array}{c}531.69 \pm 16 \\
2.22\end{array}$ & $\begin{array}{c}356.50 \pm 130 \\
13\end{array}$ & $\begin{array}{c}< \\
0.01^{* *}\end{array}$ & $\begin{array}{c}636.81 \pm 251 \\
96\end{array}$ & 0.173 & $\begin{array}{c}439.46 \pm 16 \\
4.39\end{array}$ & 0.142 & $\begin{array}{c}430.80 \pm 21 \\
1.03\end{array}$ & 0.182 & $\begin{array}{c}403.00 \pm 15 \\
6.70\end{array}$ & 0.110 \\
\hline LDH (IU/L) & $\begin{array}{c}601.88 \pm 13 \\
0.58\end{array}$ & $\begin{array}{c}1028.60 \pm 263 \\
.09\end{array}$ & $\begin{array}{c}< \\
0.01^{* *}\end{array}$ & $\begin{array}{c}664.75 \pm 194 \\
82\end{array}$ & 0.292 & $\begin{array}{c}638.38 \pm 13 \\
6.45\end{array}$ & 0.469 & $\begin{array}{c}751.40 \pm 34 \\
8.77\end{array}$ & 0.221 & $\begin{array}{c}609.00 \pm 11 \\
5.69\end{array}$ & 0.908 \\
\hline CK (IU/L) & $\begin{array}{c}276.69 \pm 12 \\
6.38\end{array}$ & $\begin{array}{c}1233.38 \pm 102 \\
5.52\end{array}$ & $\begin{array}{c}< \\
0.01^{* *}\end{array}$ & $\begin{array}{c}254.00 \pm 101 \\
87\end{array}$ & 0.580 & $\begin{array}{c}280.23 \pm 11 \\
4.48\end{array}$ & 0.938 & $\begin{array}{c}239.60 \pm 13 \\
6.30\end{array}$ & 0.487 & $\begin{array}{c}272.33 \pm 55 \\
50\end{array}$ & 0.937 \\
\hline $\begin{array}{c}\mathrm{CRE} \\
(\mu \mathrm{mol} / \mathrm{L})\end{array}$ & $\begin{array}{c}86.66 \pm 23.1 \\
3\end{array}$ & $94.27 \pm 36.44$ & 0.486 & $84.05 \pm 23.96$ & 0.757 & $\begin{array}{c}95.69 \pm 18.0 \\
8\end{array}$ & 0.260 & $\begin{array}{c}83.43 \pm 26.0 \\
9\end{array}$ & 0.745 & $\begin{array}{c}93.83 \pm 14.4 \\
3\end{array}$ & 0.489 \\
\hline $\begin{array}{c}\text { BUN } \\
(\mathrm{mmol} / \mathrm{L})\end{array}$ & $8.54 \pm 4.46$ & $8.37 \pm 4.60$ & 0.917 & $8.26 \pm 1.81$ & 0.821 & $7.06 \pm 1.39$ & 0.260 & $7.02 \pm 1.49$ & 0.309 & $7.43 \pm 1.22$ & 0.560 \\
\hline $\operatorname{ALT}(\mathrm{IU} / \mathrm{L})$ & $22.44 \pm 9.54$ & $51.40 \pm 20.79$ & $\begin{array}{c}< \\
0.01^{* *}\end{array}$ & $14.44 \pm 3.78$ & $\begin{array}{c}< \\
0.01^{* *}\end{array}$ & $14.54 \pm 4.93$ & $<0.05^{*}$ & $14.90 \pm 4.46$ & $<0.05$ & $15.67 \pm 3.56$ & 0.110 \\
\hline AST (IU/L) & $\begin{array}{c}126.56 \pm 43 \\
72\end{array}$ & $\begin{array}{c}297.69 \pm 118 \\
53\end{array}$ & $\begin{array}{c}< \\
0.01^{* *}\end{array}$ & $\begin{array}{c}123.13 \pm 35.1 \\
1\end{array}$ & 0.808 & $\begin{array}{c}154.62 \pm 58 \\
47\end{array}$ & 0.151 & $\begin{array}{c}330.60 \pm 50 \\
7.45\end{array}$ & 0.236 & $\begin{array}{c}125.00 \pm 59 \\
42\end{array}$ & 0.947 \\
\hline $\begin{array}{c}\text { PT \& } \\
\text { INR(R) }\end{array}$ & $1.44 \pm 0.44$ & $3.85 \pm 5.60$ & 0.097 & $1.61 \pm 0.17$ & 0.181 & $1.94 \pm 0.83$ & $0.049^{*}$ & $1.67 \pm 0.26$ & 0.161 & $1.59 \pm 0.11$ & 0.439 \\
\hline APTT(s) & $\begin{array}{c}33.96 \pm 10.7 \\
5\end{array}$ & $63.43 \pm 63.60$ & 0.078 & $39.68 \pm 10.63$ & 0.140 & $\begin{array}{c}80.51 \pm 98.1 \\
2\end{array}$ & 0.114 & $\begin{array}{c}40.46 \pm 11.6 \\
9\end{array}$ & 0.159 & $34.20 \pm 3.88$ & 0.958 \\
\hline
\end{tabular}

Note: RBC, red blood cell count; WBC, white blood cell count; HGB, hemoglobin; PLT, platelet; LDH, lactic dehydrogenase; CK, creatine kinase; CRE, creatinine; BUN, blood urea nitrogen; ALT, alanine aminotransferase; AST, aspartate transaminase; PT, prothrombin time; INR, international normalized ratio; APTT, activated partial thromboplastin time. ${ }^{*}, \mathrm{P}<0.05 ; * *, \mathrm{P}<0.01$. 
Table 5. TTE observation during the experimentation on sheep

\begin{tabular}{|c|c|c|c|c|c|c|c|c|c|c|c|}
\hline \multirow[b]{2}{*}{ Items } & \multirow{2}{*}{$\frac{\mathbf{0 h}(\mathbf{n}=\mathbf{1 6})}{\text { Mean } \pm \text { SD }}$} & \multicolumn{2}{|c|}{$72 h(n=16)$} & \multicolumn{2}{|c|}{ 30-day $(n=16)$} & \multicolumn{2}{|c|}{ 60-day $(n=13)$} & \multicolumn{2}{|c|}{ 90-day $(n=10)$} & \multicolumn{2}{|c|}{ 180-day $(n=6)$} \\
\hline & & $\begin{array}{c}\text { Mean } \pm \\
\text { SD }\end{array}$ & $\begin{array}{c}\mathrm{P} \\
\text { value }\end{array}$ & $\begin{array}{c}\text { Mean } \pm \\
\text { SD }\end{array}$ & $\begin{array}{c}\mathrm{P} \\
\text { value }\end{array}$ & $\begin{array}{c}\text { Mean } \pm \\
\text { SD }\end{array}$ & $\begin{array}{c}\mathrm{P} \\
\text { value }\end{array}$ & $\begin{array}{c}\text { Mean } \pm \\
\text { SD }\end{array}$ & $\begin{array}{c}\mathrm{P} \\
\text { value }\end{array}$ & $\begin{array}{c}\text { Mea } \mathrm{n} \pm \\
\text { SD }\end{array}$ & $\mathrm{P}$ value \\
\hline $\operatorname{MVMV}(\mathrm{m} / \mathrm{s})$ & $0.55 \pm 0.13$ & $0.60 \pm 0.13$ & 0.242 & $0.63 \pm 0.15$ & 0.119 & $0.55 \pm 0.11$ & 0.948 & $0.57 \pm 0.11$ & 0.737 & $0.62 \pm 0.07$ & 0.219 \\
\hline PGmean (mmHg) & $1.41 \pm 0.72$ & $1.78 \pm 0.80$ & 0.193 & $1.99 \pm 1.02$ & 0.081 & $1.48 \pm 0.53$ & 0.773 & $1.64 \pm 0.64$ & 0.436 & $1.94 \pm 0.43$ & 0.117 \\
\hline $\mathrm{PSV}(\mathrm{m} / \mathrm{s})$ & $0.82 \pm 0.18$ & $0.94 \pm 0.22$ & 0.103 & $1.00 \pm 0.25$ & $<0.05^{*}$ & $0.91 \pm 0.15$ & 0.153 & $1.01 \pm 0.18$ & $<0.05$ & $1.08 \pm 0.14$ & $<0.01^{* *}$ \\
\hline PPG (mm Hg) & $2.80 \pm 1.28$ & $3.67 \pm 1.81$ & 0.126 & $4.25 \pm 2.05$ & $<0.05^{*}$ & $3.39 \pm 1.12$ & 0.204 & $4.22 \pm 1.48$ & $<0.05$ & $4.74 \pm 1.28$ & $<0.01^{* *}$ \\
\hline MR & $0.00 \pm 0.00$ & $0.00 \pm 0.00$ & 1.00 & $0.75 \pm 1.18$ & $<0.05^{*}$ & $0.54 \pm 1.05$ & 0.089 & $0.20 \pm 0.63$ & 0.343 & $0.00 \pm 0.00$ & 1.00 \\
\hline PVL & $0.00 \pm 0.00$ & $0.06 \pm 0.25$ & 0.333 & $0.25 \pm 0.68$ & 0.164 & $0.00 \pm 0.00$ & 1.00 & $0.00 \pm 0.00$ & 1.00 & $0.00 \pm 0.00$ & 1.00 \\
\hline
\end{tabular}

Note: MVMV, mean velocity of mitral valve; PGmean, mean pressure gradient; PSV, peak systolic velocity; PPG, peak pressure gradient; MVF, mitral valve function; $\mathrm{MR}$, mitral valve regurgitation; $\mathrm{PVL}$, perivalvular leakage. *, $\mathrm{P}<0.05$; **, $\mathrm{P}<0.01$. 


\section{Figure Legends}

Figure 1. Sketch of the novel titanium sterile titanium clip device.

Figure 2. The left atrial surface of the implant site of the molding ring.

a-d. The surface of the forming ring is smooth, the stitching is firm, and there is no displacement and deformation in the 30-day's group (a), the 60-day's group (b), the 90-day's group (c), 180-day's group (d).

Figure 3. The ultrastructure of endothelial cell coating on the metal surface of titanium nail under scanning electron microscope.

a. The dynamic variation of the ultrastructure of endothelial cell coating on the metal surface of titanium nail under scanning electron microscope in the 30-day's group, the 60-day's group, the 90day's group, 180-day's group. b. Statistical analysis of the percentage of endothelialization in the tianium clip group and the manual knotting group (Mean $\pm \mathrm{SD}$ ).

Figure 4. Gross anatomical and pathological examination results of the ring 180 days after implantation.

a. Morphology of left atrial surface at the implantation site of molding ring. Two of the six titanium nails were completely coated with proliferative fibrous tissue $(\uparrow)$, red thrombosis was observed at 3 end lines $(\triangle)$. b. The tissue sections and H\&E staining of the titanium nail tip thread $(\triangle)$.

Figure 5. Histopathological examination of the molding ring at indicated timepoints after implantation.

a. Histopathological examination showed the typical microstructure of the sutures at indicated timepoints (the 30-day's group, the 60-day's group, the 90-day's group, 180-day's group). $\triangle$, fibrous tissue with granulomatous reaction; $\uparrow$, slight calcification; $\hat{z}$, chronic inflammation response. B-D. Statistical analyses of the inflammatory reaction (b), histologic reaction (c), and the number of fiber wraps (d) in the aforementioned site of suture between the tianium clip group and the manual knotting group (Mean $\pm \mathrm{SD}$ ).

Figure 6. Anatomic structures and histopathological examination of the vital organs.

a-b. Anatomic structures (a) and histopathological examination (b) of diffused renal infarction ( $\uparrow$ ). c-d. Anatomic structures of multifocal fibrous scar (c) ( $\uparrow$ ) and histopathological examination (d) of multifocal fibrous scar and calcification in the myocardium $(\uparrow)$. 
Figures

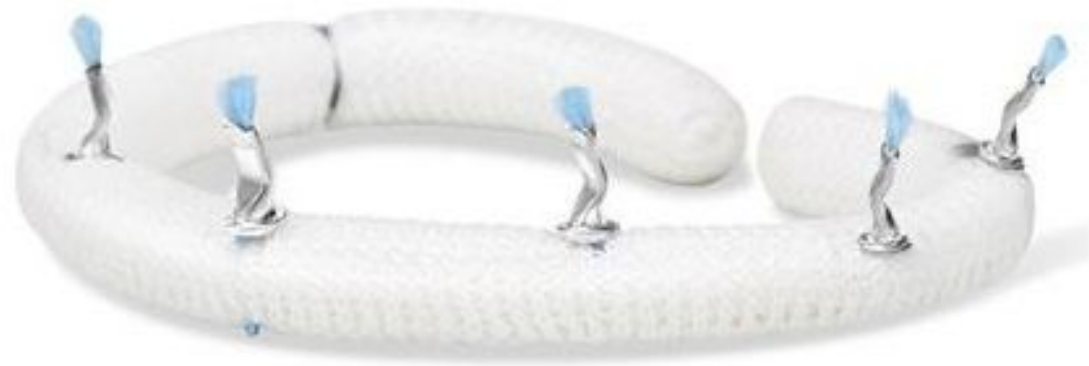

Figure 1

Sketch of the novel titanium sterile titanium clip device. 


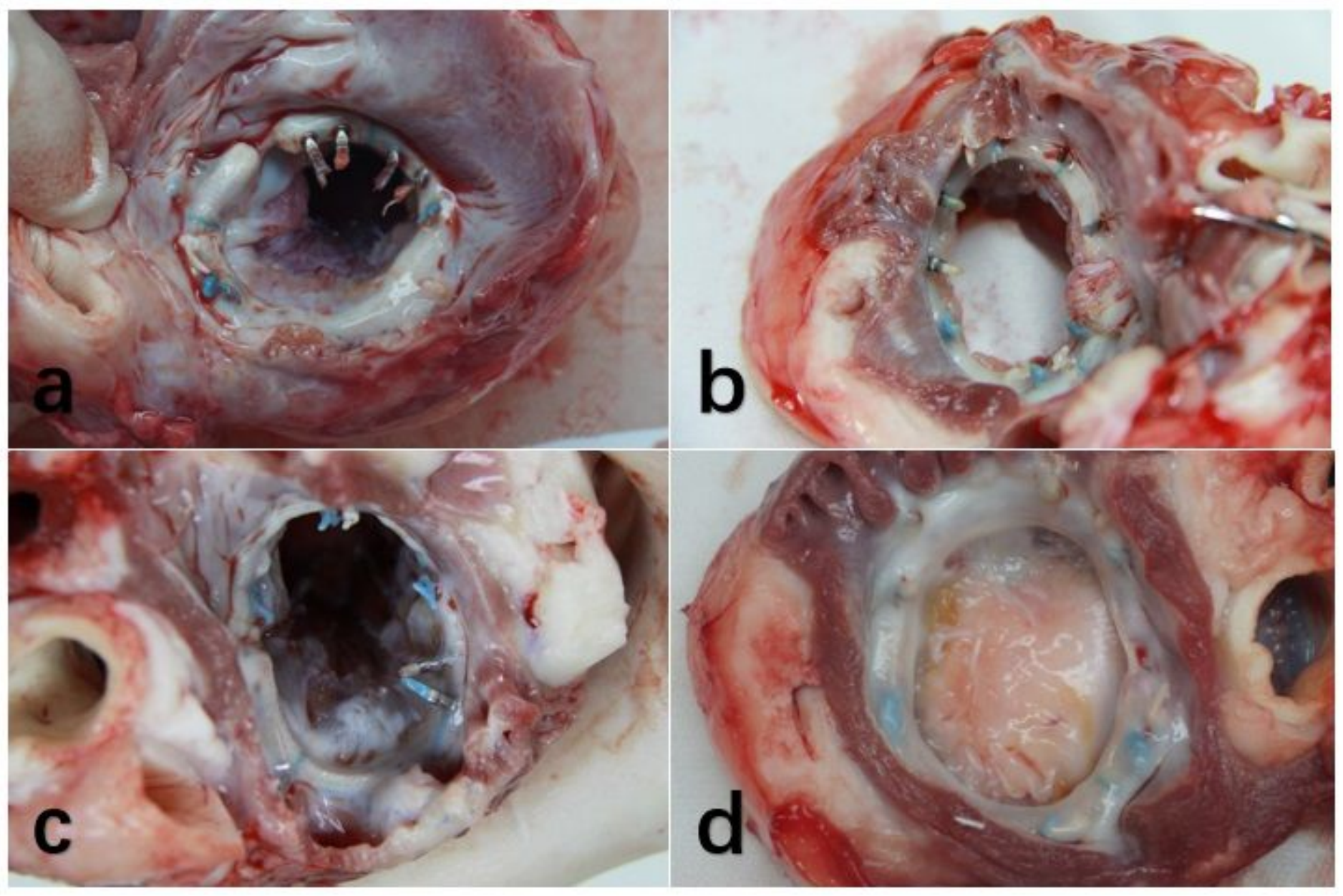

Figure 2

The left atrial surface of the implant site of the molding ring. a-d. The surface of the forming ring is smooth, the stitching is firm, and there is no displacement and deformation in the 30-day's group (a), the 60-day's group (b), the 90-day's group (c), 180-day's group (d). 

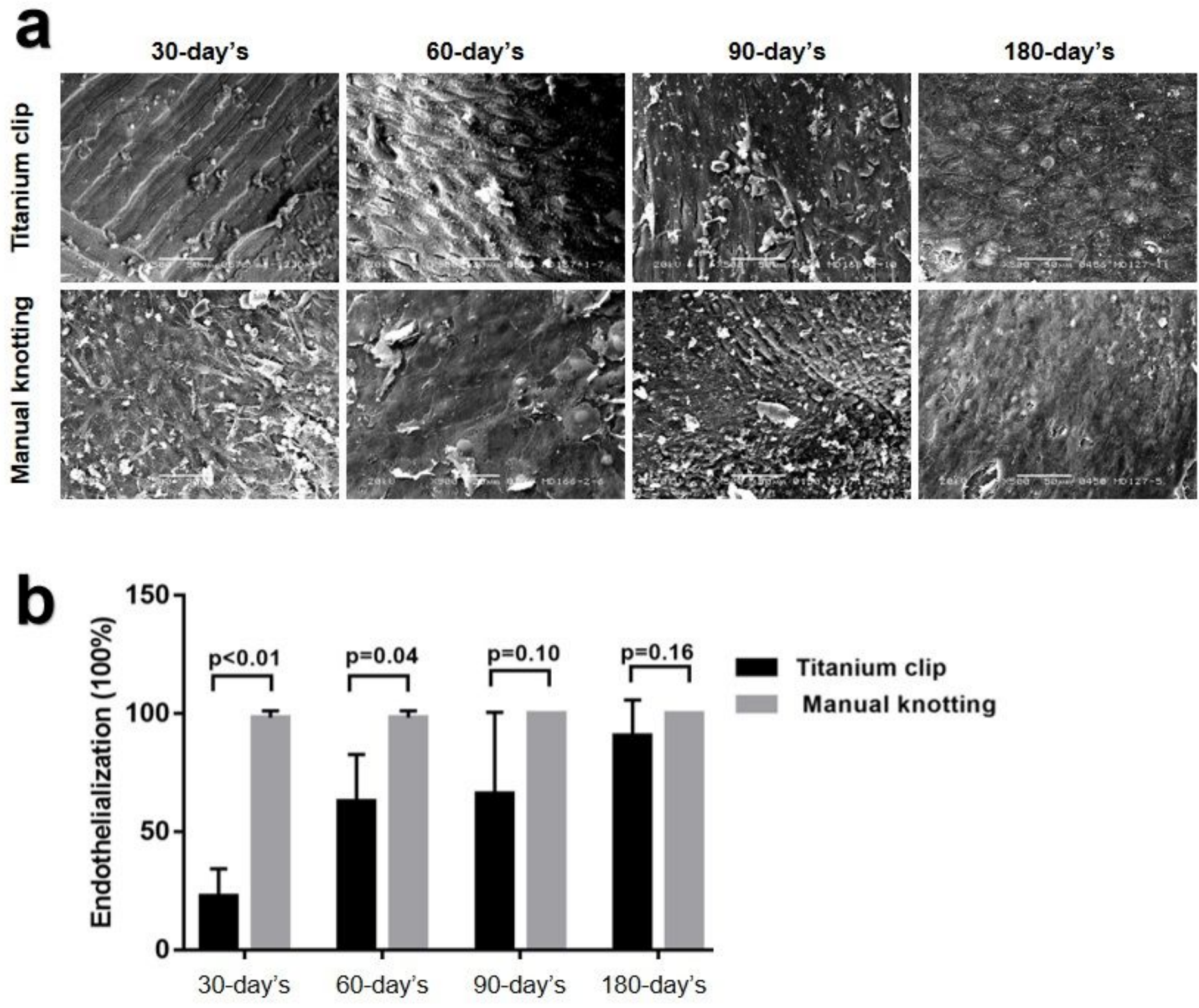

Figure 3

The ultrastructure of endothelial cell coating on the metal surface of titanium nail under scanning electron microscope. a. The dynamic variation of the ultrastructure of endothelial cell coating on the metal surface of titanium nail under scanning electron microscope in the 30-day's group, the 60-day's group, the 90- day's group, 180-day's group. b. Statistical analysis of the percentage of endothelialization in the tianium clip group and the manual knotting group (Mean $\pm S D$ ). 


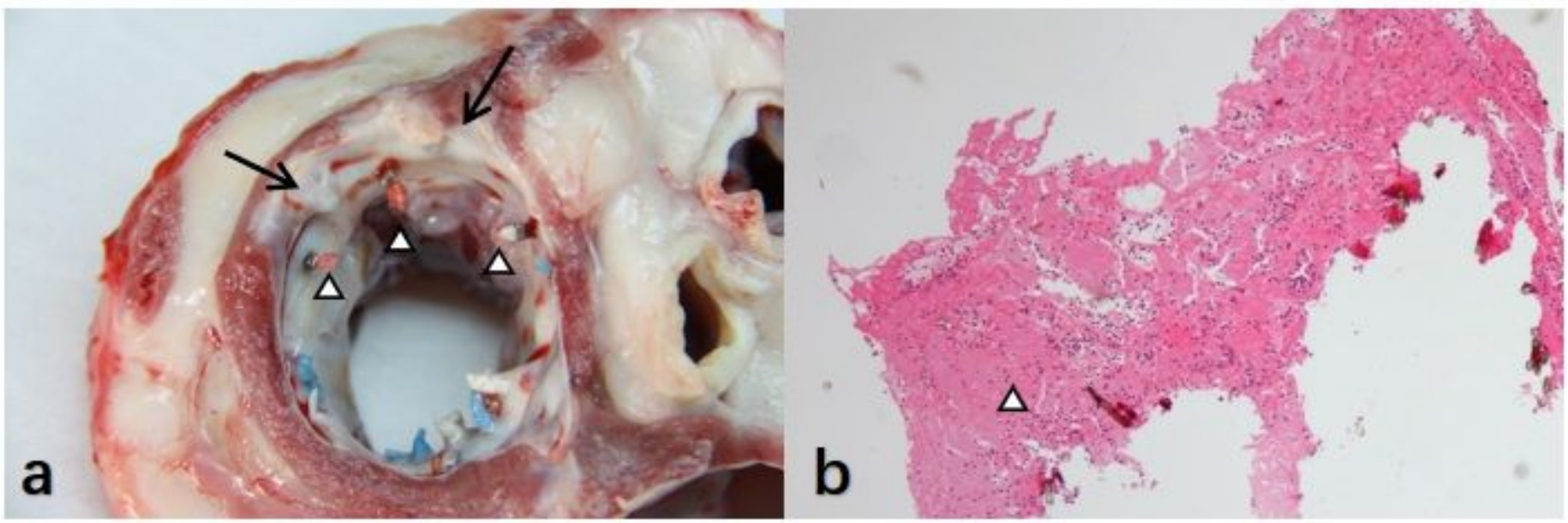

Figure 4

Gross anatomical and pathological examination results of the ring 180 days after implantation. a. Morphology of left atrial surface at the implantation site of molding ring. Two of the six titanium nails were completely coated with proliferative fibrous tissue $(\mathbb{\nabla})$, red thrombosis was observed at 3 end lines ( $)$. b. The tissue sections and H\&E staining of the titanium nail tip thread ( () . 
a
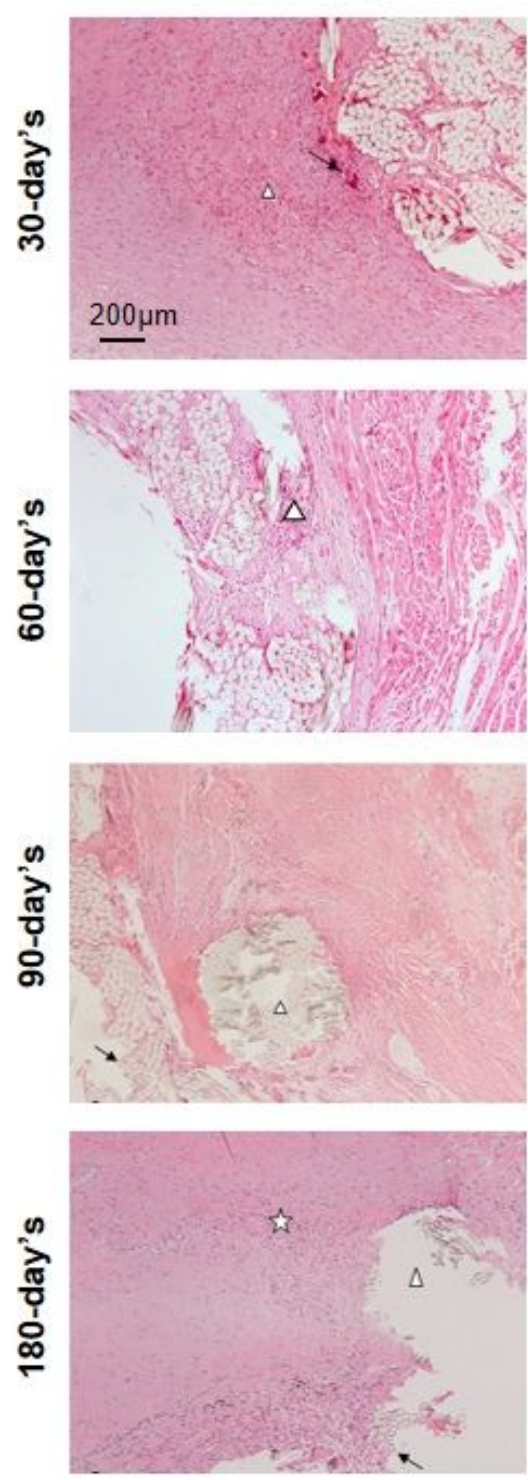

Manual knotting
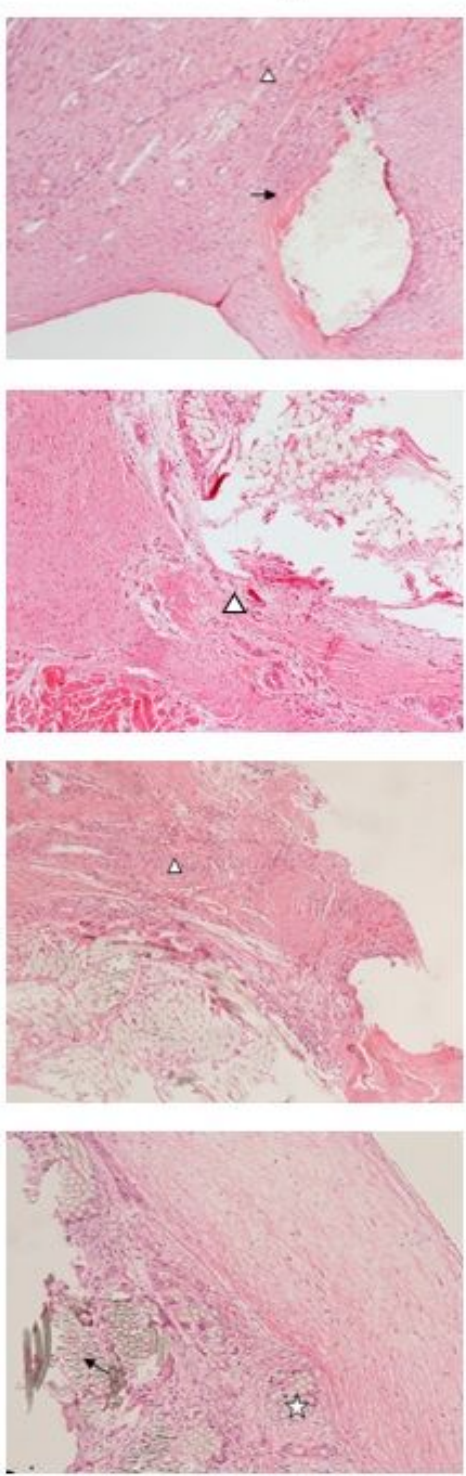

b

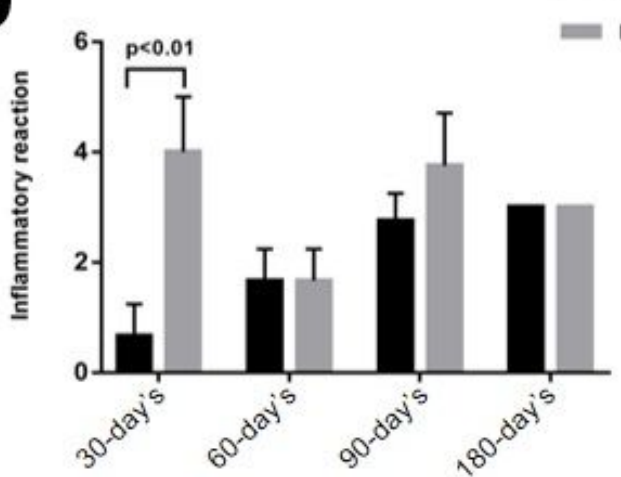

C

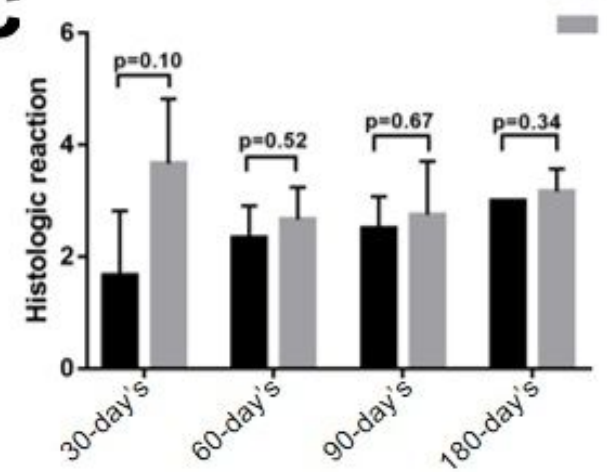

d

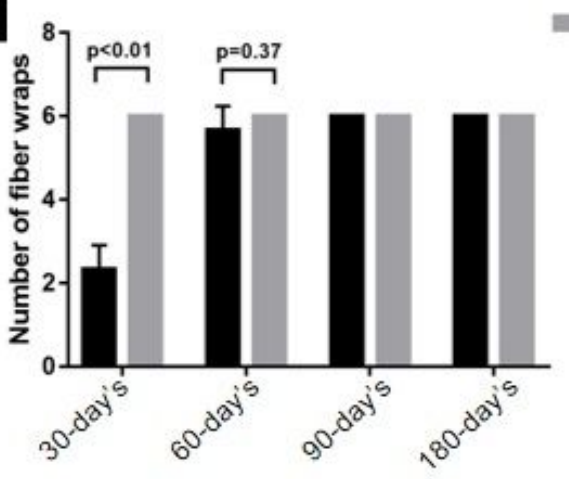

Titanium clip Manual knotting

- Titanium clip Manual knotting

\section{Figure 5}

Histopathological examination of the molding ring at indicated timepoints after implantation. a. Histopathological examination showed the typical microstructure of the sutures at indicated timepoints (the 30-day's group, the 60-day's group, the 90-day's group, 180-day's group). $\otimes$, fibrous tissue with

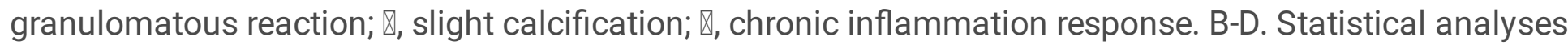
of the inflammatory reaction (b), histologic reaction (c), and the number of fiber wraps (d) in the aforementioned site of suture between the tianium clip group and the manual knotting group (Mean \pm $\mathrm{SD})$. 


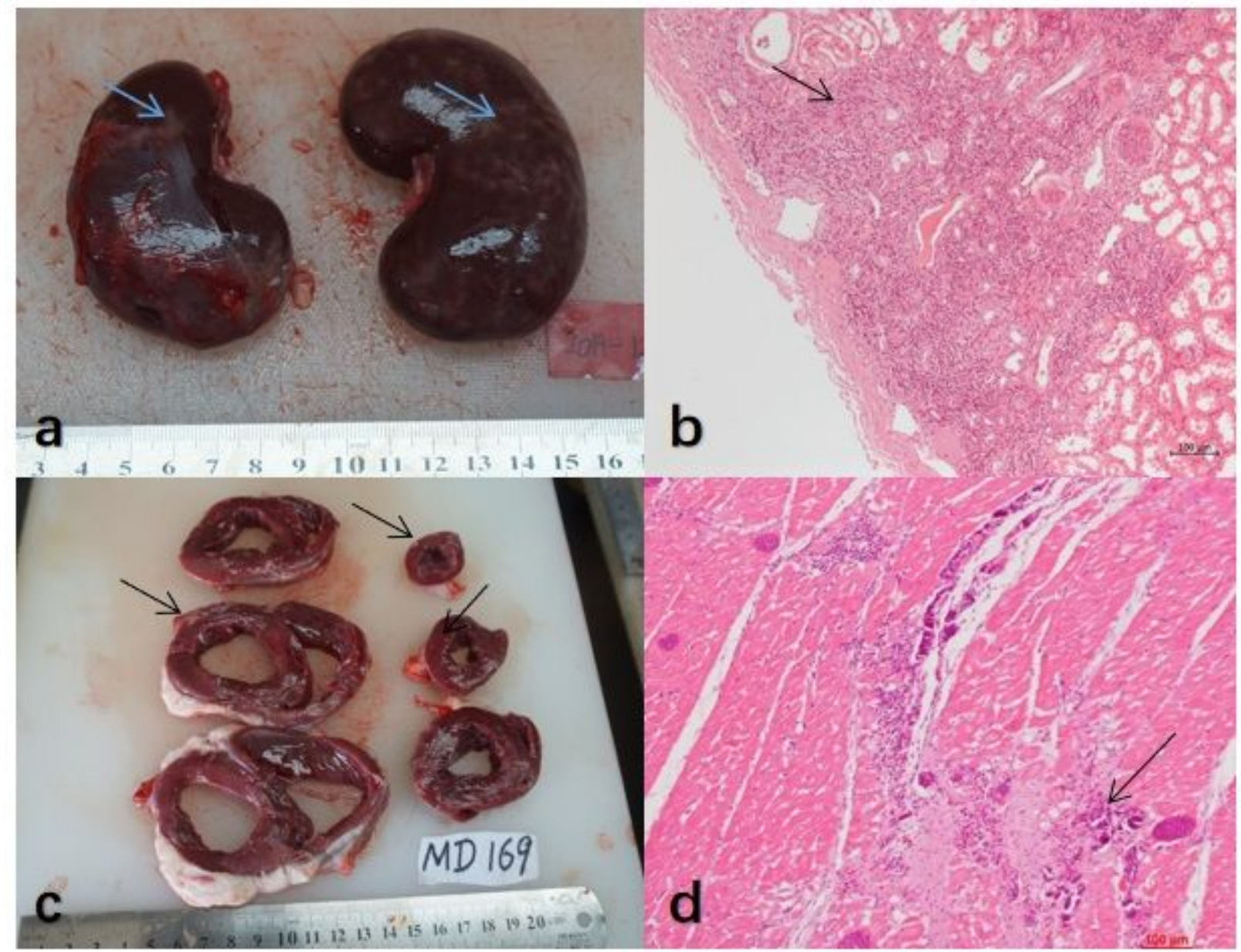

\section{Figure 6}

Anatomic structures and histopathological examination of the vital organs. a-b. Anatomic structures (a) and histopathological examination (b) of diffused renal infarction (『). c-d. Anatomic structures of multifocal fibrous scar (c) ( () and histopathological examination (d) of multifocal fibrous scar and calcification in the myocardium ( () . 